\title{
Lucanus gradivus n. sp. from Vietnam, with new records of $L$. fujitai Katsura \& Giang from Vietnam and Laos (Coleoptera, Lucanidae)
}

\author{
Jin Sato $^{1 *}$, Michele Zilioli
}

\begin{abstract}
Lucanus gradivus n.sp. from Vietnam is described. It belongs to the large of L. fortunei Saunders, 1854 species group and is closely related to L. fujitai Katsura \& Giang 2002. Lucanus gradivus differs mainly through the stronger and differently denticulated mandibles, larger and more pronounced posterolateral corners of the cephalic lobes, and the aedeagus, with longer flagellum, shorter and thinner median lobe, and longer apically curved parameres.
\end{abstract}

Key words: Lucanidae, Lucanus, new species, Vietnam.

Riassunto - Lucanus gradivus n. sp. del Vietnam, con nuove segnalazioni di L. fujitai Katsura \& Giang, 2002 da Vietnam e Laos (Coleoptera, Lucanidae).

Viene descritto Lucanus gradivus n.sp. del Vietnam. La nuova specie appartiene al grande gruppo di specie del L. fortunei Saunders, 1854 ed è strettamente affine a L. fujitai Katsura \& Giang 2002. Lucanus gradivus differisce soprattutto per le mandibole, più robuste e differentemente denticolate, gli angoli posterolaterali delle creste cefaliche, più ampie e più pronunciate e l'edeago, con flagello più lungo, lobo mediano corto e sottile e parameri più lunghi e fortementi incurvati all'apice.

Parole chiave: Lucanidae, Lucanus, nuova specie, Vietnam.

\section{INTRODUCTION}

Lucanus fujitai was originally described by Katsura \& Giang (2002) on a small series of specimens coming from Sapa, Fan Si Pan Mountains in Lao Cai Province, northern Vietnam. Since then very few specimens were collected in that area. Recently, Huang \& Chen (2013) in their monumental work on Chinese Lucanidae, recorded L. fujitai from Jinping in South-eastern Yunnan, China. In the last few years, our colleagues

\footnotetext{
1 7-11, Ipponsugimachi, Wakabayashi-ku, Sendai, 984-0828, Japan.

${ }^{2}$ Museo Civico di Storia naturale di Milano, Corso Venezia, 55, 20121 Milano, Italy.

E-mail: michele.zilioli@comune.milano.it

${ }^{*}$ Corresponding author: jintoro28@gmail.com

(C) 2018 Jin Sato, Michele Zilioli
}

Received: 29 November 2017

Accepted for publication: 4 December 2017
Thanh Luong Le, Thai Quang Nguyen and Steeve Collard provided us with several Lucanus specimens from Lai Chau and Yen Bai provinces in north Vietnam and Houaphan Province in north Laos. Among them, we identified several $L$. fujitai specimens coming from new localities and an interesting new species, belonging to the Lucanus fortunei Saunders, 1854 species-group and closely related to L. fujitai, herewith described as Lucanus gradivus n.sp.

\section{MATERIALS AND METHODS}

Pictures were taken by a Sony DSC-HX90V digital camera.

Photographs of genitalia were taken by a Canon PowerShot S50 digital camera mounted on a Leica MS5 stereomicroscope and processed through the Combine ZP software. The specimens are deposited in the following institutions or private collections:

\section{Depositories}

JSC Jin Sato Collection, Sendai, Japan.

MSNM Museo di Storia Naturale, Milano, Italy.

MZC Michele Zilioli Collection, Albizzate, Italy.

KPM Kanagawa Prefectural Museum of Natural History, Odawara, Japan

\section{Lucanus gradivus n. sp. (Fig. 1a-c)}

\section{Type material}

Holotype $\delta^{\lambda}$ : Vietnam, Mu Cang Chai, Yen Bai Prov., VI. 2015, local collector leg. (deposited at the MSNM).

\section{Paratypes}

$20 \hat{\gamma}$, same locality as the holotype, V.2015 (JSC, MZC); 1 J, Vietnam, Yen Bai Prov., VI.2015, local collector leg. (JSC); 1 Oे, same locality, VI.2017 (JSC); 2 $\hat{\sigma}^{\lambda} \hat{\jmath}$, Vietnam, Lai Chau Prov., VI.2015 (JSC); 1 ô, Vietnam, Ha Giang Prov., VI.2016 (JSC).

\section{Holotype (Fig.1-b).}

Length, including mandibles: $56.9 \mathrm{~mm}$. Length without mandibles: $37.7 \mathrm{~mm}$. Maximum head width, excluding mandibles: $17.2 \mathrm{~mm}$. 

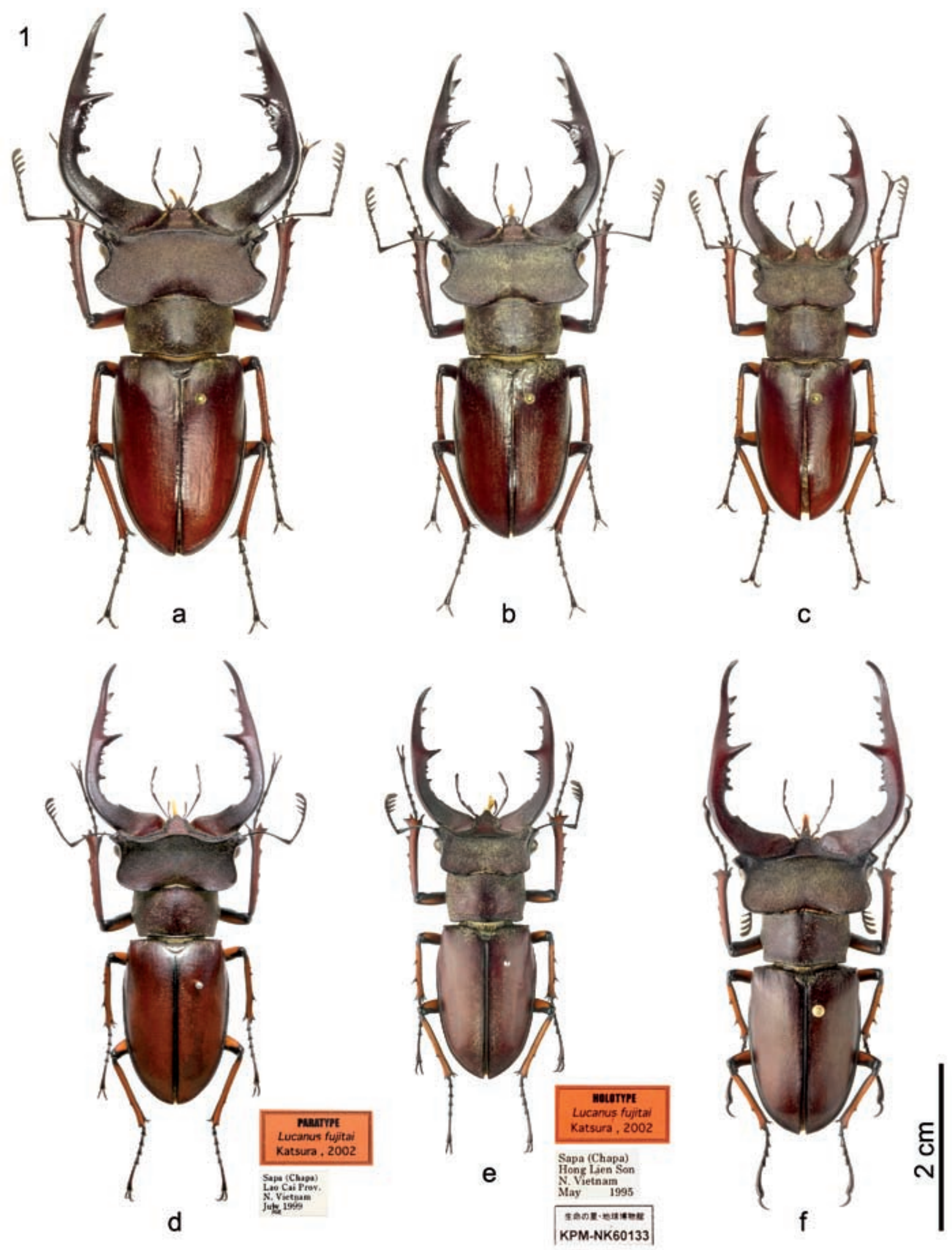

Fig. 1 - a-c) Lucanus gradivus n.sp. a, c: paratype males, JSC; b: holotype male, MSNM. d-f: Lucanus fujitai Katsura \& Giang. d: paratype male, Vietnam, Coll.Higuchi; e: holotype male, Vietnam, KPM; f: male, Laos, MZC. 
Body slender, dark reddish brown, strongly punctate throughout, coated with sparse appressed yellowish pubescence. Elytra reddish brown with a narrow lateral and sutural black border; antennae and palpi black; legs with tarsi and coxae black, femora ferrugineous with base, apex and edges black, tibiae ferrugineous with black apices.

Head. Transverse (W/L: 2.10), matt, finely and irregularly rasp-like granulose, covered by a dense yellowish appressed pubescence and ridged along most of its profile. Head laterally broadly concave, posterolaterally with strong, wide, protruding beyond the eyes level, lobes; posterior margin widely concave. Anterolateral cephalic angles strongly protruding, more prominent than the eyes. Ocular canthus shorter than half eye's diameter. Frons trapezoidal, slightly concave, fused with the epistoma. Transverse clypeal ridge strong, medially interrupted, laterally projecting as two blunt teeth; epistoma triangular, its apex rounded and fringed with yellowish hairs. Frontal ridge bisinuate, feebly raised and weakly convex. Mandible long, moderately robust, strongly bent at its proximal third, then almost straight up to its slightly curved apex; feebly shining, distinctly microsculptured proximally and sparsely punctured distally, with short, relatively sparse yellowish pubescence basally. Median tooth strong, triangular, sharp, slightly tilted forwards and upwards, placed after the midlength. Inner mandibular margin with a proximal strong serrated carina followed by a diastema, a strong blunt tooth, a serrated edge tipped by the median tooth, and 2-3 distal small denticles. Upper apical tooth bent upwards, with a sharp, well-marked dorsal carina; lower apical tooth shorter, conical, slightly directed forwards.

Antennal club 4-jointed; joints 8-10 bearing a strong, long, pubescent lamella; joint 7 with a shorter and thinner lamella, pubescent only anteriorly and with scattered setae elsewhere. Mentum wide, trapezoidal, matt, finely and irregularly granulose, covered with sparse yellowish pubescence, which is longer along mentum sides; anterior margin medially strongly convex and with broadly rounded corners.

Thorax. Pronotum transverse (W/L: 1.74), matt, finely punctured, coated with moderately dense, appressed yellowish pubescence; median longitudinal depression shallow, distinct in its anterior half, almost wanting in the posterior one; anterior corners rounded, posterior ones slightly protruding. Prosternal apophysis strong, prominent, apically rounded, laterally covered with yellowish pubescence. Scutellum transverse, rounded posteriorly, finely punctate and microreticulate, coated with appressed yellowish pubescence, except for a narrow smooth lateral margin. Elytra finely and densely punctate throughout, superficially microreticulate, coated with sparse yellowish pubescence, which is much longer and denser proximally. Shoulders toothed.

Legs slender, fairly shining, microreticulate with large, shallow, unevenly scattered punctures and with sparse, short yellowish pubescence, even shorter on fore tibiae. Fore tibiae with four (left) or five (right) spines on their outer edge, mid tibiae three-spinose; hind tibiae with two very small and weakly protruding preapical teeth.

Aedeagus robust (total length $5.97 \mathrm{~mm}$ ) (Fig. 2), with short and apically widened flagellum; median lobe slender, shorter than parameres; the latter strongly curved, apically protruding.

\section{Paratype males}

Consistent with the holotype except for the usual allometric differences. Larger male with more pronounced morphological characters, and smaller one with, e.g., mandibles less curved and only feebly denticulated.

\section{Derivatio nominis}

This species is named after "Gradivus" a cult epithet of the god of war Mars, used here in reference of the combative and robust appearance.

\section{Comparative notes}

Lucanus gradivus n. sp. is closely related to $L$. fujitai and both belong to the very large Lucanus fortunei species-group. However, L. gradivus n. sp. can be easily distinguished at glance from L. fujitai through the comparison Table 1.

Tab. 1 - Comparison between Lucanus gradivus n. sp. and Lucanus fujitai.

\begin{tabular}{|l|l|}
\hline $\begin{array}{l}\text { Lucanus gradivus n. } \\
\text { sp. (Fig. 1 a-c) }\end{array}$ & $\begin{array}{c}\text { Lucanus fujitai Kat- } \\
\text { sura \& Giang (Fig. 1 d-f; } \\
\text { Fig. 3) }\end{array}$ \\
\hline $\begin{array}{l}\text { Mandible moderately } \\
\text { robust. Surface weakly } \\
\text { shining, distinctly mi- } \\
\text { crosculptured proximally } \\
\text { and sparsely punctate dis- } \\
\text { tally. }\end{array}$ & $\begin{array}{l}\text { Mandibles more slender. } \\
\text { Surface matt with a distinct } \\
\text { microsculpture, more dense } \\
\text { proximally. }\end{array}$ \\
\hline $\begin{array}{l}\text { Inner mandibular mar- } \\
\text { gin with a proximal strong } \\
\text { serrated carina followed by } \\
\text { a diastema, a strong blunt } \\
\text { tooth, a serrated edge tipped } \\
\text { by the median tooth, and } \\
\text { 2-3 distal small denticles. }\end{array}$ & $\begin{array}{l}\text { Inner mandibular mar- } \\
\text { ginarmed carina followed by } \\
\text { andema, a strong blunt } \\
\text { tooth, 2-3 small separated } \\
\text { denticles, the median tooth } \\
\text { and 2-4 distal small den- } \\
\text { ticles. }\end{array}$ \\
\hline
\end{tabular}

Frontal ridge bisinuate, feebly raised and weakly convex.

Frontal ridge bisinuate, strongly raised and more convex medially.

Clypeal ridge strong, Clypeal ridge barely vismedially interrupted, later- ible, laterally forming just ally distinctly projecting as distinct angles. two blunt teeth.

Posterolateral cephalic lobes strongly widened and protruding beyond the level of the eyes.

Aedeagus with short and apically widened flagellum; median lobe slender, about half as long as the relatively long parameres.

Posterolateral cephalic lobes less widened and not protruding beyond the level of the eyes.

Aedeagus with very short and weakly apically widened flagellum; median lobe stouter, about $3 / 4$ as long as the relatively short parameres.

New records of Lucanus fujitai Katsura \& Giang (Fig. 1 d-f) 

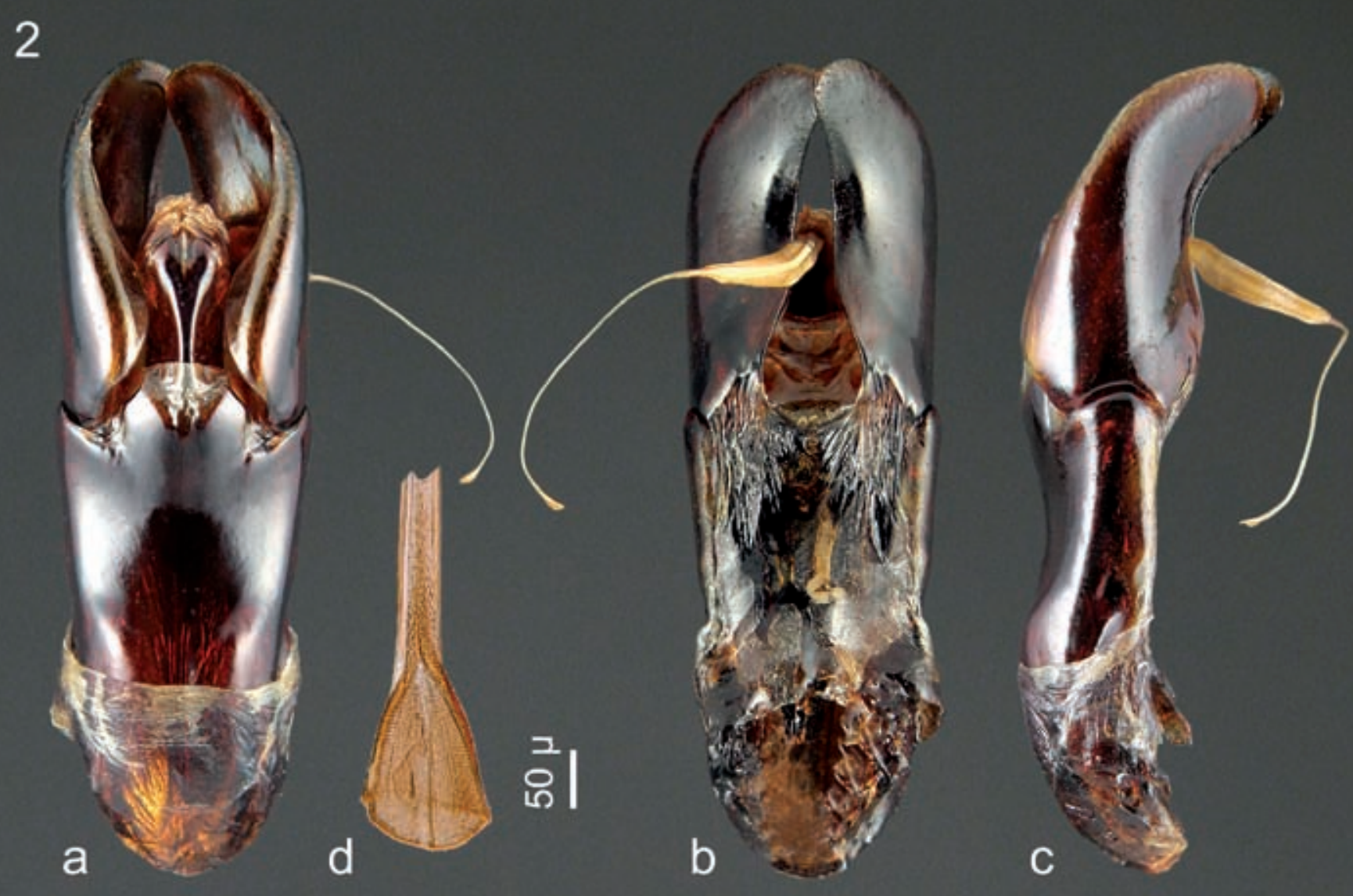

3
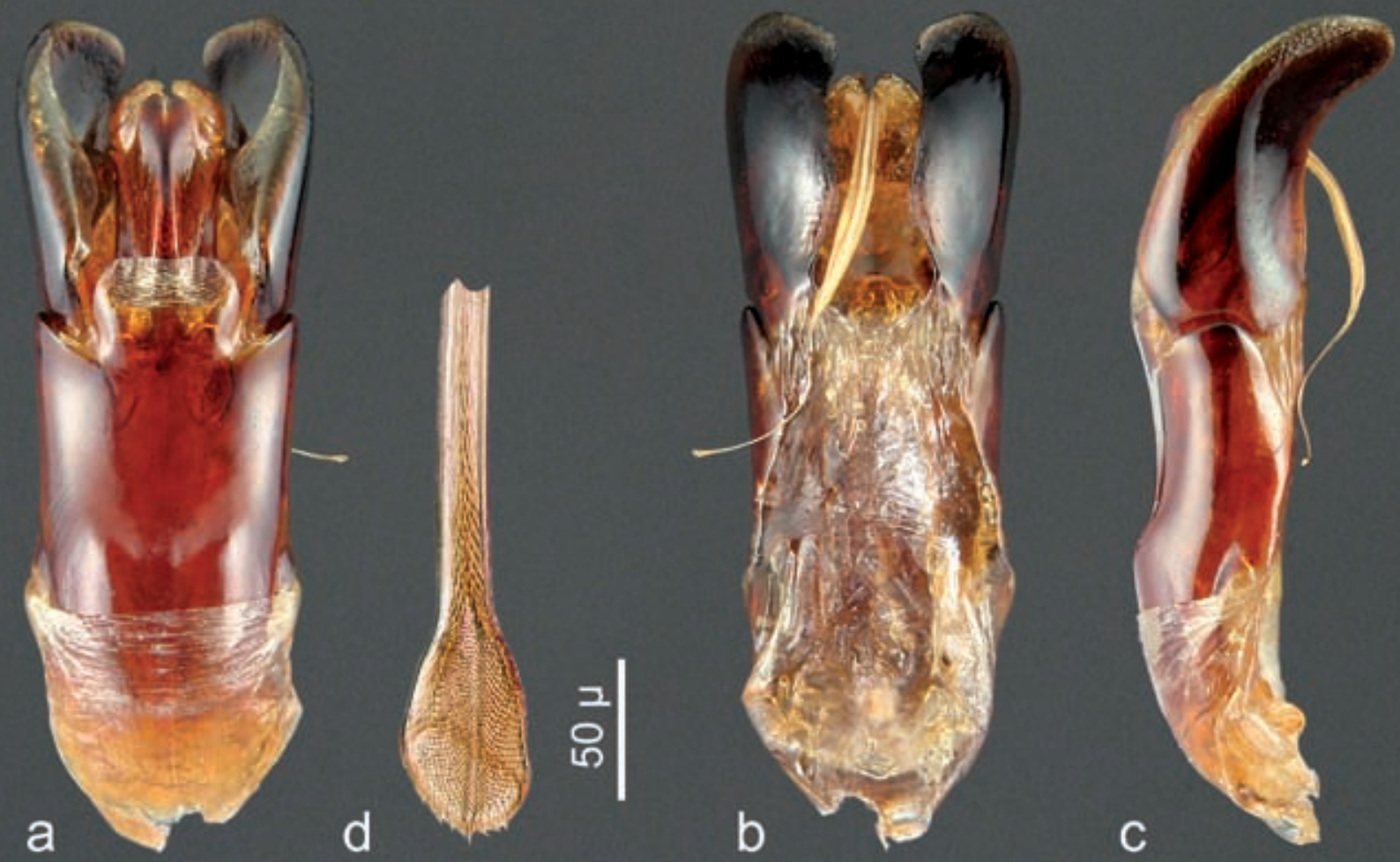

$\frac{E}{E}$

Fig. 2-3 - 2) Lucanus gradivus n.sp. Aedeagus - a) ventral view, b) dorsal view, c) lateral view, d) apex of flagellum. 3) Lucanus fujitai Katsura \& Giang. Aedeagus. a) ventral view, b) dorsal view, c) lateral view, d) apex of flagellum. 
Vietnam: $9 \widehat{\partial} \widehat{\jmath}$, Mu Cang Chai Mt. $1700 \mathrm{~m}$, Yen Bai prov., V-VI.2017, local collector leg.; $39 \hat{\partial} \partial^{\lambda}$, same locality, V.2016; $7 \AA \widehat{\partial}$, Mu Cang Chai Mt. H. Than Uyen district, Lai Chau prov., VI.2015, local collector leg.; 8 $\hat{\partial}$, Yen Bai province, IV.2015, local collector leg.; 3 ô, $\hat{\text {, }}$, same locality, V.2014; 1 ô, Van Chan Mt. Van Chan district, Yen Bai prov., IV.2013, local collector leg.; all preserved in JSC.

Laos: Mt. Phu Pan Tin, 1950 m, VI.2015, S.Collard leg. (MZC).

In the above mentioned localities, L. fujitai is sympatric with L. gradivus n. sp. and Lucanus marazziorum Zilioli (2012).

\section{Acknowledgements}

We are deeply grateful to Dr. Haruki Karube (Kanagawa Prefectural Museum of Natural History, Odawara, Japan), who gave us the opportunity to study the holotype specimen of Lucanus fujitai, and to publish its photo; to Mr. Akihiro Higuchi for the photo of the paratype of the same species. Also, we wish to thank Fabrizio Rigato (MSNM) and Cinzia Monte (Florence) for reviewing our manuscript.

\section{REFERENCES}

Huang H. \& Chen C.C., 2013 - Further research on the genera Lucanus Scopoli and Eolucanus Kurosawa from China, with the description of two new species. In: Stag Beetles of China II. Huang H. \& Chen C.C. (eds). Formosa Ecological Company: 1-34.

Katsura N. \& Giang D.L., 2002 - Notes on the genus Lucanus (Coleoptera, Lucanidae) from northern Vietnam with descriptions of two new species. Gekkan Mushi, Tokyo, 378: 2-14.

Zilioli M., 2012 - Contribution to the knowledge of the stag-beetles of the genus Lucanus from Laos, with description of Lucanus marazziorum n. sp. (Coleoptera Lucanidae). Atti della Societá Italiana di Scienze Naturali e del Museo Civico di Storia Naturale, Milano, 153 (2): 267-276. 